\title{
A Strategy for Optimizing the Combination of Active Components Based on Chinese Medicinal Formula Sheng-Mai-San for Myocardial Ischemia
}

\author{
Fang Li Xiao-Xue Fan Chun Chu Yu Zhang Jun-Ping Kou Bo-Yang Yu \\ State Key Laboratory of Natural Products, Jiangsu Key Laboratory of TCM Evaluation and Translational \\ Research, Department of Complex Prescription of TCM, School of Traditional Chinese Pharmacy, China \\ Pharmaceutical University, Nanjing, P.R. China
}

\section{Key Words}

Sheng-Mai-San - Multicomponent drug design - Myocardial ischemia - Quantitative pharmacology

\begin{abstract}
Background/Aims: Traditional Chinese medicine (TCM) has been used in clinical practice for thousands of years and has accumulated considerable knowledge concerning the in vivo efficacy of targeting complicated diseases. TCM formulae are a mixture of hundreds of chemical components with multiple potential targets, essentially acting as a combination therapy of multi-component drugs. However, the obscure substances and the unclear molecular mechanisms are obstacles to their further development and internationalization. Therefore, it is necessary to develop new modern drugs based on the combination of effective components in TCM with exact clinical efficacy. In present study, we aimed to detect optimal ratio of the combination of effective components based on Sheng-Mai-San for myocardial ischemia. Methods: On the basis of preliminary studies and references of relevant literature about Sheng-Mai-San for myocardial ischemia, we chose three representative components (ginsenoside Rb1 $(\mathrm{G})$, ruscogenin $(\mathrm{R})$ and schisandrin $(\mathrm{S})$ ) for the optimization design studies. First, the proper proportion of the combination was explored in different myocardial ischemia mice induced by isoproterenol and pituitrin based on orthogonal design. Then, the different proportion combinations were further optimized through uniform design in a multi-model and multi-index mode. Finally, the protective effect of combination was verified in three models of myocardial ischemia injured by ischemia/reperfusion, chronic intermittent hypoxia and acute infarction. Results: The optimized combination GRS (G: 6 mg/kg, R: 0.75 mg/kg, S: 6 mg/kg) obtained by experimental screening exhibited a significant protective effect on myocardial ischemia injury, as evidenced by decreased myocardium infarct size, ameliorated histological features, decreased myocardial myeloperoxidase (MPO) and malondiadehyde (MDA), calcium overload, and decreased serum lactate dehydrogenase (LDH), creatine kinase MB isoenzyme (CK-MB), cardiac troponin I (cTn-I) activity. In addition, the interactions of three components

Jun-Ping Kou

Jiangsu Key Laboratory of TCM Evaluation and Translational Research,

China Pharmaceutical University, 639 Longmian Road, Nanjing (P.R. China)

Tel. +86-25-86185158, E-Mail junpingkou@cpu.edu.cn, boyangyu59@163.com
\end{abstract}




\section{Cellular Physiology Cell Physiol Biochem 2018;45:1455-1471

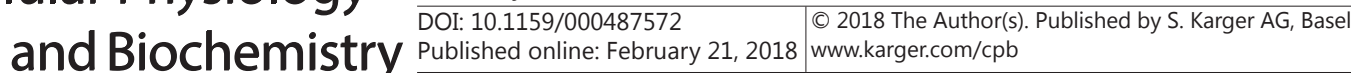 \\ Li et al.: A Strategy for Optimizing the Combination for Myocardial Ischemia}

in combination GRS were also investigated. The combination, compared to $G, R$ and $S$, could significantly reduce the concentration of serum CK-MB and CTn-I, and decrease myocardial infarct size, which demonstrated the advantages of this combination for myocardial ischemia. Conclusion: Our results demonstrated that the optimized combination GRS could exert significant cardioprotection against myocardial ischemia injury with similar effect compared to Sheng Mai preparations, which might provide some pharmacological evidences for further development of new modern Chinese drug for cardiovascular diseases basing on traditional Chinese formula with affirmative therapeutic effect.

\section{Introduction}

Ischemic heart disease (IHD) is a public health concern with a rising incidence that leads to high morbidity and mortality worldwide, which is closely associated with cardiac dysfunctions, especially myocardial infarction, ischemia reperfusion injury and heart failure [1]. It is widely accepted that myocardial ischemia (MI) injury is a pathological process that includes energy deficit, inflammation, oxidative stress, cardiomyocyte death, involving inherently multiple and complex signaling pathways [2]. Currently, angiotensin-converting enzyme inhibitors, statins, antioxidant, $\beta$-blockers and $\mathrm{Ca}^{2+}$ channel blockers are the major agents for the treatment of MI injury in clinic, while the mortality and morbidity of the syndrome remain unacceptably high [3]. This might be partially due to the reason that each of these agents affects a single target or signaling pathway. Therapeutic strategies aiming at multi-pathways and multi-targets would possess stronger therapeutic efficacies for complex multifactorial diseases.

Traditional Chinese medicine (TCM) offers obvious advantages in this respect. Combination therapy has been advocated for more than 2, 500 years [4]. However, the unclearness of bioactive components and functional mechanism of TCM agents, in particular formulae, limits their modernization and internationalization. The production of effective combinatorial mixtures to manipulate multiple disease targets has obtained increasing attentions in the research community of drug discovery and development [5]. Thus, it is an efficient way to develop the effective drug combinations in multicomponent drug design based on the TCM with definite clinical efficacy. Such study is in line with the concept of translational medicine, which has great theory value and application prospect. The preclinical efficacy and mechanism study of four main ingredients including baicalin, jasminoidin, cholic acid and mother of pearl, which was derived from Qing-Kai-Ling for the treatment of cerebral ischemia, was carried out early [6]. In addition, the main effective components combination from Chinese medicinal formula Realgar-Indigo naturalis, comprising of tetraarsenic tetrasulfide, indirubin and tanshinone IIA, yielded synergy in the treatment of promyelocytic leukemia [7]. All these researches promoted the design of multicomponent drugs from natural products in TCM.

Pharmacometrics (or mathematical pharmacology) is a branch subject of pharmacology which quantitatively studies the law of pharmacological effects via mathematical means, which widely applied in various fields of pharmaceutical research [8-10]. The application of statistical experimental design approaches and mathematical models may extremely contribute to the efficient searches for the potent drug combinations. TCM in the treatment of myocardial ischemia diseases mainly include four categories: active compounds extracted from herbs, single herbs, decoctions and patent drugs made up of Chinese herbs [11]. ShengMai-San, which is composed of Ginseng Radix Et Rhizoma Rubra, Ophiopogonis Radix, and Schisandrae Chinensis Fructus, is one of the famous complex prescription in TCM. Previous studies demonstrated that Sheng-Mai-San showed effectiveness for the treatment of myocardial ischemia through anti-oxidation, anti-inflammation, inhibition of apoptosis, and enhancing the tolerance of ischemic tissue to hypoxia [12-14]. Sheng-Mai Injection (SMI) and YiQiFuMai Powder Injection (YQFM) are modern preparations re-developed based on formula Sheng-Mai-San, which have been widely used in clinic to treat cardiovascular 
diseases [15]. However, there still exist some key issues about its quality stabilization and clinical safety owing to the complex components. Developing an optimum composition of several active components from TCM for the maximum therapeutic efficacy is a critical step in the discovery of multicomponent drug from natural sources.

In the present study, we chose three representative components, including ginsenoside $\mathrm{Rb} 1$ (Ginsenosides of Red ginseng-G), ruscogenin (Saponins of Radix ophiopogonis-R)and schisandrin (Lignans of Fructus schisandrae-S), for the optimization design studies using quantitative pharmacological methods on the basis of preliminary studies and references of relevant literatures about Sheng-Mai-San for myocardial ischemia [16-20], so as to detect the optimum proportion of effective components and provide a potential cardioprotective cocktail. Moreover, our findings will also offer some pharmacological evidence for further development of patent multicomponent drug for myocardial ischemia diseases.

\section{Materials and Methods}

Drugs and reagents

Ginsenoside $\mathrm{Rb} 1$ and schisandrin were purchased from Nanjing Zelang Bio-Technology Co., Ltd (Nanjing, China). Ruscogenin was isolated in our laboratory and the purity was determined to be higher than $99 \%$ by HPLC. Isoproterenol and 2, 3,5-triphenyltetrazolium chloride (TTC) were purchased from Sigma-Aldrich (St. Louis, MO, USA). Pituitrin was obtained from Shanghai No.1 Biochemical \& Pharmaceutical Co., Ltd (Shanghai, China). YQFM was provided by Tasly Pharmaceutical Co., Ltd. with the batch number of 20121210. The kits for determination of lactate dehydrogenase (LDH), malondialdehyde (MDA), creatine kinase (CK), creatine kinase isoenzyme (CK-MB), myeloperoxidase (MPO), nitric oxide (NO), calcium ion $\left(\mathrm{Ca}^{2+}\right)$ and cardiac troponin I (cTn-I) were obtained from Nanjing Jiancheng Bioengineering Institute (Nanjing, China).

Male ICR mice and C57BL/6 mice (18-22 g) were both purchased from Model Animal Research Centre of Yangzhou University (Yangzhou, Jiangsu, China). The animals were housed in a standard vivarium with free access to food and water. Prior to experiments, animals were randomized into experimental groups. All procedures were conducted in accordance with the National Institutes of Health Guidelines for the Care and Use of Laboratory Animals.

\section{Orthogonal experimental design}

Active ingredients (G, R and S) were selected as the three factors for orthogonal experiment, and each factor sets three doses for three levels (Table 1). As shown in Table 2, the experiment was arranged according to the orthogonal table $L_{9}\left(3^{4}\right)$.

\section{Uniform experimental design}

Active ingredients (G, R and S) were selected as the three factors and each factor set eight levels for uniform design. As shown in Table 3, the experiment was arranged following the uniform table $\mathrm{U}_{9}\left(9^{6}\right)$.

Table 1. Three-factor and three-level of orthogonal experiment

\begin{tabular}{lccc}
\hline Leve & \multicolumn{3}{c}{ Factor } \\
l & $\begin{array}{c}\mathrm{A} \\
\mathrm{G}(\mathrm{mg} / \mathrm{kg})\end{array}$ & $\begin{array}{c}\mathrm{B}(\mathrm{mg} / \mathrm{kg}) \\
\mathrm{S}(\mathrm{mg} / \mathrm{kg})\end{array}$ \\
\hline 1 & 6 & 0.3 & 3 \\
2 & 12 & 0.6 & 6 \\
3 & 24 & 1.2 & 12 \\
\hline
\end{tabular}

Table 2. Arrangement of orthogonal experiment

\begin{tabular}{lcccc}
\hline Group & G Rb1 & Rus & SA & Error \\
\hline 1 & 1 & 1 & 1 & 1 \\
2 & 1 & 2 & 2 & 2 \\
3 & 1 & 3 & 3 & 3 \\
4 & 2 & 1 & 2 & 3 \\
5 & 2 & 2 & 3 & 1 \\
6 & 2 & 3 & 1 & 2 \\
7 & 3 & 1 & 3 & 2 \\
8 & 3 & 2 & 1 & 3 \\
9 & 3 & 3 & 2 & 1 \\
\hline
\end{tabular}

Table 3. Arrangement of uniform experiment

\begin{tabular}{lccc}
\hline Group & $\begin{array}{c}\mathrm{A} \\
\mathrm{G}\end{array}$ & $\begin{array}{c}\mathrm{B} \\
\mathrm{R}\end{array}$ & $\begin{array}{c}\mathrm{C} \\
\mathrm{mg} / \mathrm{kg}\end{array}$ \\
$\mathrm{mg} / \mathrm{kg}$ & $\mathrm{mg} / \mathrm{kg}$ \\
\hline 1 & 0 & 0.15 & 18 \\
2 & 3 & 0.45 & 12 \\
3 & 6 & 0.75 & 6 \\
4 & 9 & 1.05 & 0 \\
5 & 12 & 0 & 21 \\
6 & 15 & 0.3 & 15 \\
7 & 18 & 0.6 & 9 \\
8 & 21 & 0.9 & 3 \\
Control & 0 & 0 & 0 \\
Model & 0 & 0 & 0 \\
YQFM & \multicolumn{3}{c}{$2.84 \mathrm{~g} / \mathrm{kg}$} \\
\hline
\end{tabular}




\section{Cellular Physiology Cell Physiol Biochem 2018;45:1455-1471

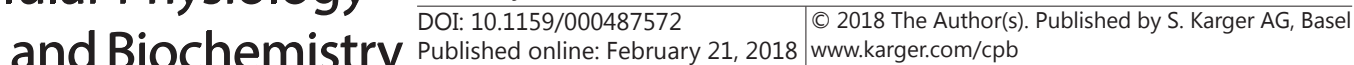 and Biochemistry

\section{Animal models and drug intervention}

Acute myocardial ischemia model. Myocardial ischemia models were induced by isoproterenol (ISO) or pituitrin (PIT) in ICR mice, and the orthogonal design was used in these two models to explore the proper proportion of three components $G, R$, and $S$. The uniform design was implemented in these two models to optimize the proper proportion of three components $G, R$, and S. Mice were divided randomly into different groups: the sham group, the model group and the orthogonal experimental 1-9 groups or the uniform experimental 1-8 groups. The sham group was administrated with $5 \%$ ethanol-saline $(10 \mathrm{ml} / \mathrm{kg})$ intraperitoneally for 3 days; the model group was given with isoproterenol (25 $\mathrm{mg} / \mathrm{kg}$ ) subcutaneously or with pituitrin $(20 \mathrm{U} / \mathrm{kg}$ ) intraperitoneally for 3 days; and the orthogonal or uniform experimental groups were administrated with different GRS combination $(10 \mathrm{ml} / \mathrm{kg})$ intraperitoneally, then given isoproterenol or pituitrin after 30 min for 3 days.

Myocardial ischemia reperfusion injury model. The MI/R model was produced as described previously [21]. Briefly, C57BL/6 mice were anesthetized intraperitoneally with chloral hydrate $(400 \mathrm{mg} / \mathrm{kg})$. Myocardial ischemia was produced by exteriorizing the heart with a left thoracic incision followed by making a slipknot (6-0 silk) around left anterior descending coronary artery. After 30 min of ischemia, the slipknot was released and followed by $24 \mathrm{~h}$ of reperfusion. Mice were divided randomly into seven groups: the sham group, the MI/R group, the YQFM group $(1.06 \mathrm{~g} / \mathrm{kg}$ ) and the different GRS combination group. The sham group was given the same surgical procedures without ligating left anterior descending coronary artery. Both the sham and the MI/R mice received the same volume of saline alone. All drugs were administered via intraperitoneally within $10 \mathrm{~min}$ at the beginning of reperfusion.

Chronic intermittent hypoxia model. As reported [22], in addition to the control group, all ICR mice in each group were exposed to chronic intermittent hypoxia (nadir 7\% to peak 8\% oxygen, 20 min per day, continuous hypoxia for 28 days) in a chamber. All drugs were administered via intraperitoneally once a day.

Acute myocardial infarction model. The model was generated as previously described [21]. Briefly, C57BL/ 6 mice were anesthetized intraperitoneally with chloral hydrate. For myocardial ischemia, a slipknot was tied around the left anterior descending coronary artery 3-4 mm from its origin utilizing a 6-0 silk suture. Successful ligation of the coronary artery was confirmed by the occurrence of ST-segment elevation in electrocardiogram. After ligation, the heart was immediately placed back into the intrathoracic space followed by manual evacuation of air and closure of muscle and the skin. All drugs were administered via intraperitoneally after $20 \mathrm{~min}$ of ischemia.

\section{Survival time detection and electrocardiogram measurement}

After injection of isoproterenol for $15 \mathrm{~min}$ on the third day, the mice were placed in the wild-mouth bottle containing soda lime, then the bottles were sealed. The survival time of each group under hypoxic condition were recorded. After administrated with different GRS combination for 30 min on the third day, the mice were anesthetized intraperitoneally with $4 \%$ chloral hydrate. Then the mice were connected with the BL-420S biological function experimental instrument and the changes in the amplitude of T wave were detected.

Measurement of LDH, CK, CK-MB and cTn-I in serum and MPO, MDA, NO, Ca ${ }^{2+}$ release in myocardium

At the end of the experiment, blood was collected and serum was separated by centrifugation. LDH, CK, CK-MB and cTn-I were detected according to the manufacturer's instructions, respectively. Mice were sacrificed after blood collection, then the heart tissue was removed, homogenized using normal saline as the medium and centrifuged at $2500 \mathrm{rpm}$ for $10 \mathrm{~min}$. Finally, the supernatant was applied to measure the levels of MPO, MDA, $\mathrm{NO}$ and $\mathrm{Ca}^{2+}$ following the manufacturer's description.

\section{Histopathologic examination, measurement of cardiac index and myocardial infarct size}

At the end of the experiment, the heart tissue was removed, fixed by $10 \%$ formalin and embedded with paraffin, sliced into pieces of $5 \mu \mathrm{m}$ thick, eosin-stained and mounted. The histopathological changes were detected by optical microscope. For measurement of cardiac index, the heart tissue was rapidly excised and washed away residual blood with normal saline, then weighed after dried with filter paper.

Twenty-four hours after ischemia, the heart was quickly excised, frozen at $-70{ }^{\circ} \mathrm{C}$, and the ventricular tissue was cut into five slices perpendicular to the long axis of the heart. The heart sections were then incubated individually using a 24-well culture plate with $1 \%$ TTC solution at $37{ }^{\circ} \mathrm{C}$ for $15 \mathrm{~min}$, and photographed 


\section{Cellular Physiology Cell Physiol Biochem 2018;45:1455-1471 \\ \begin{tabular}{l|l|l} 
and Biochemistry Published online: February 21, 2018 & $\begin{array}{l}\text { (c) } 2018 \text { The Author(s). Published by S. Karger AG, Basel } \\
\text { www.karger.com/cpb }\end{array}$ \\
\hline
\end{tabular}}

Li et al.: A Strategy for Optimizing the Combination for Myocardial Ischemia

digitally. Red parts in the heart stained by TTC indicated ischemic but viable tissue. While staining negative areas represented infarcted myocardium. Areas of infarct size were measured by computerized planimetry. The size of infarction area was expressed as percentage of the total LV area.

\section{Statistical analysis}

All experiments were performed in triplicate and data were expressed as the mean \pm SEM. Statistical analysis was carried out using Student's two-tailed t-test for comparison between two groups and one-way analysis of variance (ANOVA), followed by Dunnett's test when the data involved three or more groups. $P<$ 0.05 was defined as significant.

\section{Results}

Preliminary screening on the proper proportion of the multicomponent drug GRS by orthogonal design

Orthogonal experimental screening results of the combination GRS on isoproterenol and pituitrin induced myocardial ischemia models. The orthogonal design was applied in two models to explore the proper proportion of GRS choosing survival time and T wave AUC as indexes. As shown in Fig. 1A, after ISO injection, survival time significantly decreased in ISO group, while combination 7 substantially extended the survival time of myocardial ischemia mice. And there was no significant differences between the other combination groups and model group. Meanwhile, after injected with PIT, as illustrated in Fig. 1B, electrocardiogram $\mathrm{T}$ wave is markedly higher in model group compared with the control group. There were differences between the combination of different proportions in improving pituitrin-induced myocardial ischemia. It was found that combination 4 could significantly reduce the T-wave elevation, better than any other combination.

Variance analysis of the orthogonal results. In ISO-induced myocardial ischemia model, $\mathrm{K}$ and $\mathrm{R}$ value were calculated according to the comprehensive analysis of average survival time in each group (Table 4). It was indicated that the best combination is $A_{3} B_{1} C_{3}(G 24 \mathrm{mg} /$ $\mathrm{kg}, \mathrm{R} 0.3 \mathrm{mg} / \mathrm{kg}, \mathrm{S} 12 \mathrm{mg} / \mathrm{kg}$ ) in accordance with the $\mathrm{K}$ value. Meanwhile, ruscogenin was the main factor of the combination's effectivity ranking by the R value. As illustrated in Table 5 , compound $\mathrm{R}$ and $\mathrm{G}$ exerted a main role in the combination GRS according to the variance analysis, which exhibited remarkable effect on survival time in ISO-induced myocardial ischemia mice. In addition, according to the intuitive analysis diagram (Fig. 1C),

Fig. 1. Results of orthogonal experiment in acute myocardial ischemia model. (A) Effects of different orthogonal experimental groups on survival time in isoproterenol-induced myocardial ischemia mice. (B) Effects of different orthogonal experimental groups on electrocardiogram $\mathrm{T}$ wave AUC in pituitrin-induced myocardial ischemia mice. (C) Intuitive analysis of orthogonal design in isoproterenol-induced myocardial ischemia mice. (D) Intuitive analysis of orthogonal design in pituitrin-induced myocardial ischemia mice. Arrangement of orthogonal experiment (group 1-9) was shown in Table 2. Results were presented as mean $\pm \mathrm{SEM}$. ${ }^{\#} \mathrm{P}<0.01$ vs. Control group without myocardial ischemia injury, ${ }^{*} \mathrm{P}<0.05,{ }^{* *} \mathrm{P}<0.01$ vs. group treated with myocardial ischemia injury alone. $n=10$.

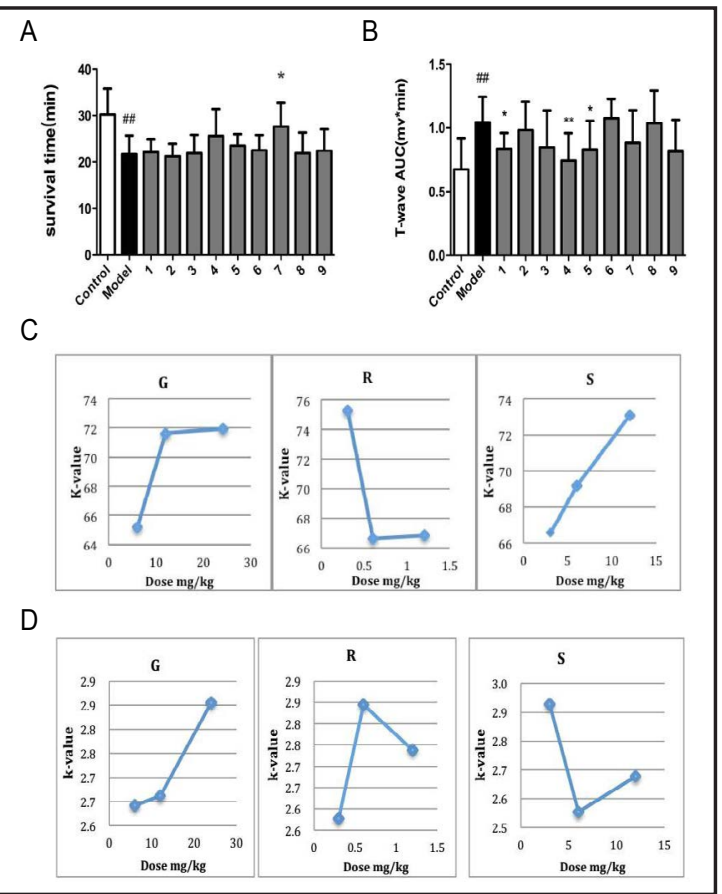


Table 4. Analysis of orthogonal design in ISO model

\begin{tabular}{|c|c|c|c|c|c|}
\hline \multirow{2}{*}{ Group } & A & B & C & D & \multirow{2}{*}{ Survival time } \\
\hline & G & $\mathrm{R}$ & $\mathrm{s}$ & Error & \\
\hline Control & & & & & 30.22 \\
\hline Model & & & & & $21.67 \# \#$ \\
\hline 1 & 1 & 1 & 1 & 1 & 22.11 \\
\hline 2 & 1 & 2 & 2 & 2 & 21.22 \\
\hline 3 & 1 & 3 & 3 & 3 & 21.89 \\
\hline 4 & 2 & 1 & 2 & 3 & 25.56 \\
\hline 5 & 2 & 2 & 3 & 1 & 23.56 \\
\hline 6 & 2 & 3 & 1 & 2 & 21.75 \\
\hline 7 & 3 & 1 & 3 & 2 & $27.67^{*}$ \\
\hline 8 & 3 & 2 & 1 & 3 & 21.89 \\
\hline 9 & 3 & 3 & 2 & 1 & 22.44 \\
\hline K1 & 65.22 & 75.34 & 66.56 & 68.11 & 208.90 \\
\hline K2 & 71.68 & 66.67 & 69.22 & 71.45 & $\mathrm{CT}=208.90^{\wedge} 2 / 9$ \\
\hline K3 & 72.00 & 66.89 & 73.12 & 69.34 & $=4848.80$ \\
\hline $\mathrm{R}$ & 6.78 & 8.67 & 6.56 & 3.34 & \\
\hline $\mathrm{K} 1^{2}$ & 4253.65 & 5676.12 & 4430.23 & 4638.97 & \\
\hline $\mathrm{K} 2^{2}$ & 5138.02 & 4444.89 & 4791.41 & 5105.10 & \\
\hline $\mathrm{K} 3^{2}$ & 5184.00 & 4474.27 & 5346.53 & 4808.04 & \\
\hline $\mathrm{Q}=\left(\mathrm{K} 1^{2+} \mathrm{K} 2^{2+} \mathrm{K} 3^{2}\right) / 3$ & 4858.56 & 4865.09 & 4856.06 & 4850.70 & \\
\hline $\mathrm{S}=\mathrm{Q}-\mathrm{CT}$ & 9.76 & 16.29 & 7.26 & 1.90 & \\
\hline
\end{tabular}

taking large dose range of $\mathrm{G}(12-24 \mathrm{mg} /$ $\mathrm{kg})$, small dose range of $\mathrm{R}(0.3-0.6 \mathrm{mg} / \mathrm{kg})$ and large dose range of $S(6-12 \mathrm{mg} / \mathrm{kg})$ in combination GRS was better.

Meanwhile, in PIT-induced myocardial ischemia model, $\mathrm{K}$ and $\mathrm{R}$ value were also calculated according to the comprehensive analysis of average area under the curve of electrocardiogram $\mathrm{T}$ wave in each group (Table 6). According to the $\mathrm{K}$ value, the best combination is $A_{1} B_{1} C_{2}(G 6 \mathrm{mg} /$ $\mathrm{kg}$, R $0.3 \mathrm{mg} / \mathrm{kg}, \mathrm{S} 6 \mathrm{mg} / \mathrm{kg}$ ). As shown in Table 7 with variance analysis, compound schisandrin was the main factor of effectivity in accordance with the $\mathrm{R}$ value, however, the effect was weak with no statistical difference. Moreover, according to the intuitive analysis diagram (Fig. 1D), taking small dose range of G (6-12 $\mathrm{mg} /$ $\mathrm{kg})$, small dose range of $\mathrm{R}(0.3-0.6 \mathrm{mg} / \mathrm{kg})$ and large dose range of $\mathrm{S}(6-12 \mathrm{mg} / \mathrm{kg})$ in combination GRS was better.

Multiple regression analysis of the orthogonal results. The dose of each group in orthogonal design was standardized before the multiple regression modeling (Table 8). The modeling process of data analysis on survival time in ISO-induced myocardial ischemia mice was shown in Table 9. And the model parameters of final prediction effect were exhibited in Table 10. Evaluation of final prediction effect model using graphic method was illustrated in Fig. 2A. The predictive value $\left(\mathrm{E}_{\text {pred }}\right)$ in each group were in good agreement with the mean between groups $\left(\mathrm{E}_{\text {group }}\right)$, as well as the $\mathrm{E}_{\text {pred }}$ and the measured value of individual $\left(\mathrm{E}_{\mathrm{obs}}\right)$, the prediction value of individual $\left(\mathrm{E}_{\text {ipred }}\right)$ and $\mathrm{E}_{\mathrm{obs}}$. Most of the weighted residuals WRES were between -2 and 2 , and there was no scattered points between -4 and 4 , which indicated that no outliers existed. In addition, the final efficacy prediction equation is: $\mathrm{Y}=21.744+1.516 \mathrm{X} 1-2.028 \mathrm{X} 2+1.825 \mathrm{X} 3$, therefore, the best efficacy was 26.601 when $\mathrm{X} 2$ used the minimum dose of 0.429 , meanwhile, $\mathrm{X} 1$ and $\mathrm{X} 3$ applied the maximum
Table 5. Variance analysis of orthogonal design in ISO model. Because of fe (the degree of freedom of Error) $<5$, in order to improve the sensitivity of the F-test, therefore, the level was increased and $\mathrm{F}$ value was calculated between $\mathrm{F}_{0.1}$ and $\mathrm{F}_{0.2}$ on the table. The factors that have an impact on the index were marked with " $\Delta$ "

\begin{tabular}{lcccccc}
\hline & Sum of squares & Freedom & Mean square & F-value & Significant & Optimal level \\
\hline $\mathrm{G}$ & 9.76 & 2 & 4.88 & 5.14 & $\triangle$ & $3(24 \mathrm{mg} / \mathrm{kg})$ \\
$\mathrm{R}$ & 16.29 & 2 & 8.15 & 8.57 & $\triangle$ & $1(0.3 \mathrm{mg} / \mathrm{kg})$ \\
$\mathrm{S}$ & 7.26 & 2 & 3.63 & 3.82 & & $3(12 \mathrm{mg} / \mathrm{kg})$ \\
Error & 1.90 & 2 & 0.95 & & & \\
Sum & 35.21 & $\mathrm{~F}_{0.1}(2,2)=9$ & $\mathrm{~F}_{0.2}(2,2)=4$ & & & \\
\hline
\end{tabular}

Table 6. Analysis of orthogonal design in PIT model

\begin{tabular}{|c|c|c|c|c|c|}
\hline \multirow{2}{*}{ Group } & $\mathrm{A}$ & B & $\mathrm{C}$ & $\mathrm{D}$ & T-wave AUC \\
\hline & G & $\mathrm{R}$ & s & Error & $\mathrm{mv}$ min \\
\hline Control & & & & & 0.675 \\
\hline Model & & & & & $1.043^{\# \#}$ \\
\hline 1 & 1 & 1 & 1 & 1 & $0.814^{*}$ \\
\hline 2 & 1 & 2 & 2 & 2 & 0.982 \\
\hline 3 & 1 & 3 & 3 & 3 & 0.846 \\
\hline 4 & 2 & 1 & 2 & 3 & $0.743^{* *}$ \\
\hline 5 & 2 & 2 & 3 & 1 & $0.827^{*}$ \\
\hline 6 & 2 & 3 & 1 & 2 & 1.077 \\
\hline 7 & 3 & 1 & 3 & 2 & 1.004 \\
\hline 8 & 3 & 2 & 1 & 3 & 1.036 \\
\hline 9 & 3 & 3 & 2 & 1 & 0.815 \\
\hline K1 & 2.642 & 2.576 & 2.927 & 2.456 & 8.159 \\
\hline K2 & 2.662 & 2.845 & 2.554 & 3.063 & $\mathrm{CT}=8.159^{\wedge} 2 / 9$ \\
\hline K3 & 2.855 & 2.738 & 2.678 & 2.640 & $=7.397$ \\
\hline $\mathrm{R}$ & 0.213 & 0.268 & 0.373 & 0.607 & \\
\hline $\mathrm{K} 1^{2}$ & 6.980 & 6.638 & 8.569 & 6.032 & \\
\hline $\mathrm{K} 2^{2}$ & 7.089 & 8.092 & 6.524 & 9.383 & \\
\hline K32 & 8.150 & 7.496 & 7.169 & 6.969 & \\
\hline $\mathrm{Q}=\left(\mathrm{K} 1^{2+} \mathrm{K} 2^{2+} \mathrm{K} 3^{2}\right) / 3$ & 7.406 & 7.409 & 7.421 & 7.461 & \\
\hline $\mathrm{S}=\mathrm{Q}-\mathrm{CT}$ & 0.009 & 0.012 & 0.024 & 0.065 & \\
\hline
\end{tabular}

Table 7. Variance analysis of orthogonal design in PIT model

\begin{tabular}{lcccccc}
\hline & Sum of squares & Freedom & Mean square & F-value & Significant & Optimal level \\
\hline G & 0.009 & 2 & 0.005 & 0.142 & $1(6 \mathrm{mg} / \mathrm{kg})$ \\
R & 0.012 & 2 & 0.006 & 0.188 & $1(0.3 \mathrm{mg} / \mathrm{kg})$ \\
S & 0.024 & 2 & 0.012 & 0.372 & $2(6 \mathrm{mg} / \mathrm{kg})$ \\
Error & 0.065 & 2 & 0.032 & & \\
Sum & 0.11 & & & & & \\
\hline
\end{tabular}


Table 8. Standardization of dose in orthogonal design

\begin{tabular}{lccc}
\hline Group & G & R & S \\
\hline 1 & 0.429 & 0.429 & 0.429 \\
2 & 0.429 & 0.857 & 0.857 \\
3 & 0.429 & 1.714 & 1.714 \\
4 & 0.857 & 0.429 & 0.857 \\
5 & 0.857 & 0.857 & 1.714 \\
6 & 0.857 & 1.714 & 0.429 \\
7 & 1.714 & 0.429 & 1.714 \\
8 & 1.714 & 0.857 & 0.429 \\
9 & 1.714 & 1.714 & 0.857 \\
\hline
\end{tabular}

Fig. 2. Evaluation of final prediction effect model by using graphic method in isoproterenol (A) and pituitrin (B) induced myocardial ischemia mice. Effect verification of the selected combination with different dosages in myocardial ischemia mice induced by pituitrin. Positive drug SMI (970 mg/kg), combination with high dosage $36.3 \mathrm{mg} / \mathrm{kg}$ (G:R:S, 24:0.3:12), combination with medium dosage $18.15 \mathrm{mg} /$ $\operatorname{kg}(\mathrm{G}: \mathrm{R}: \mathrm{S}, 12: 0.15: 6)$ and combination with low dosage 12.1 $\mathrm{mg} / \mathrm{kg}$ (G:R:S, 8:0.1:4) were administered (ip) for 3 days. At the third day, mice were administered with pituitrin (ip). After 1 $\mathrm{h}$, blood and tissue samples were collected for detection. (C) Serum LDH activity. (D) Serum CK activity. (E) Myocardial MDA content. (F) Myocardial $\mathrm{Ca}^{2+}$ content. (G) Myocardial MPO activity. Results were presented as mean \pm SEM. ${ }^{\#} \mathrm{P}<0.05, \quad{ }^{\#} \mathrm{P}<0.01$ vs. Control group without myocardial ischemia injury, ${ }^{*} \mathrm{P}<0.05,{ }^{*} \mathrm{P}<0.01$ vs. group treated with myocardial ischemia injury alone. $\mathrm{n}=10$.

Table 9. Analysis of modeling process in ISO model. X1: G; X2: R; X3: S

\begin{tabular}{lcccccc}
\hline & $\mathrm{p}$ & $\mathrm{R}^{2}$-adj(\%) & $\mathrm{SS}-\mathrm{R}$ & $\mathrm{S}$ & $\begin{array}{c}\text { P-value } \\
\text { (partial F-test) }\end{array}$ & Model selection \\
\hline Base item (X1-X3) & & 11.9 & 232.429 & & & Final model \\
Bring into all items & 3 & 9.4 & 243.347 & 3.983 & 0.876 & \\
Delete X1X2 and X1X3 & 1 & 11.6 & 243.323 & 3.959 & 0.407 & \\
\hline
\end{tabular}

Table 10. Model parameters of final prediction effect in ISO model

\begin{tabular}{lcccc}
\hline Parameter & Estimated value & SE & P-value & Remark \\
\hline Expectation effect parameter & & & & \\
B0 & 21.744 & 0.987 & 0.000 & Baseline effect \\
B1 & 1.516 & 0.749 & 0.046 & Model parameter of X1 \\
B2 & -2.028 & 0.760 & 0.009 & Model parameter of X2 \\
B3 & 1.825 & 0.754 & 0.018 & Model parameter of X3 \\
Random effect parameter & & & & \\
$\sigma$ & 2.173 & & & Intraindividual variation \\
$\omega$ & 3.045 & & & Interindividual variation \\
\hline
\end{tabular}

Table 11. Analysis of modeling process in PIT model

\begin{tabular}{lcccccc}
\hline & $\mathrm{p}$ & $\mathrm{R}^{2}$-adj(\%) & $\mathrm{SS}-\mathrm{R}$ & $\mathrm{S}$ & $\begin{array}{c}\text { P-value } \\
\text { (partial F-test) }\end{array}$ & Model selection \\
\hline Base item (X1-X3) & & 3.8 & 0.350 & & & Final model \\
Bring into all items & 3 & 2.0 & 0.428 & 0.234 & 0.701 & \\
Delete X1X2 and X1X3 & 1 & 2.9 & 0.362 & 0.234 & 0.641 & \\
\hline
\end{tabular}

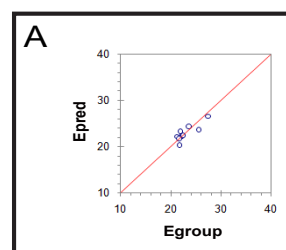

B
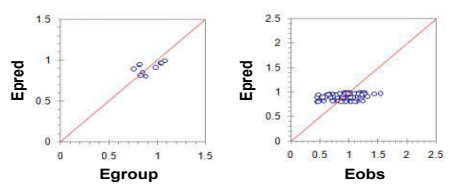

C

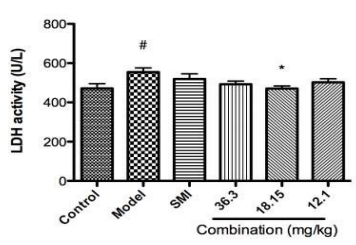

$\mathrm{D}$

E

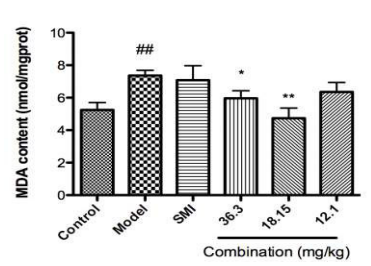

F

G

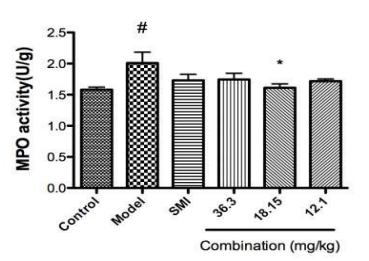

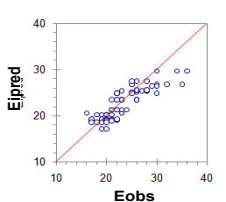
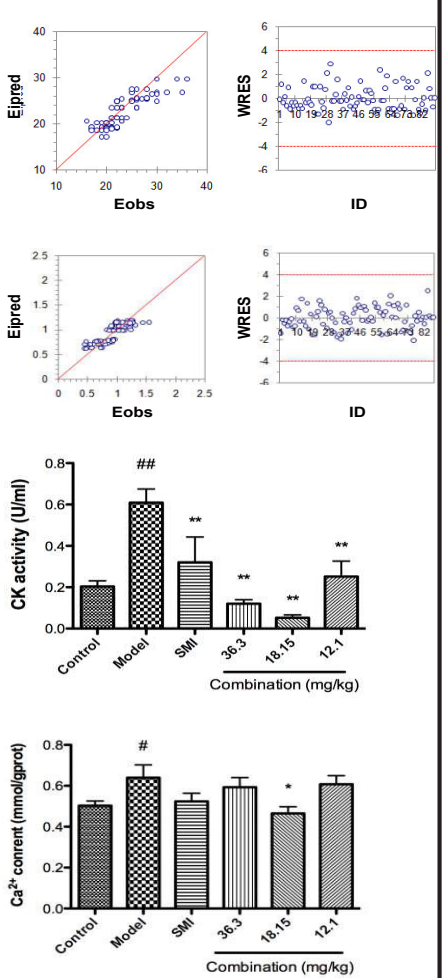
dose of 1.714 . The 95\% PI range was $18.477 \sim 34.724$. Consequently, we got the optimal combination G (24 mg/kg): R $(0.3 \mathrm{mg} /$ $\mathrm{kg})$ : S (12 mg/kg), in which compound $\mathrm{R}$ exerted a more significant role than compound $\mathrm{S}$ and $\mathrm{G}$.

The modeling process of data analysis on $\mathrm{T}$ wave AUC in PIT-induced myocardial ischemia mice was shown in Table 11. The analysis results showed that there was no interactive items included in the base item X1 (G), X2 (R) and X3 (S). And the model parameters of final prediction effect were exhibited in Table 12. Evaluation of final prediction effect model using graphic method was illustrated in Fig. 2B. Similarly, the $\mathrm{E}_{\text {pred }}$ in each group matched well with the $\mathrm{E}_{\text {group }}$, so did the $\mathrm{E}_{\text {pred }}$ and the $\mathrm{E}_{\text {obs' }}$ the $\mathrm{E}_{\text {ipred }}$ and $\mathrm{E}_{\text {obs }}$. Moreover, the final efficacy prediction equation is: $\mathrm{Y}=0.969+0.005 \mathrm{X} 1+0.040 \mathrm{X} 2$ $0.111 \mathrm{X} 3$, thus, the best efficacy was 0.798 when $\mathrm{X} 1$ and $\mathrm{X} 2$ used the minimum dose of 0.429 , meanwhile, X3 applied the maximum dose of 1.714 . The 95\% PI range was 0.320 1.276. Consequently, we got the optimal combination G $(6 \mathrm{mg} / \mathrm{kg}): \mathrm{R}(0.3$ $\mathrm{mg} / \mathrm{kg}): \mathrm{S}(12 \mathrm{mg} / \mathrm{kg})$, in which compound $S$ played a more significant role.

Activity verification of the selected optimal combination GRS on pituitrin-induced myocardial ischemia. As illustrated in Fig. 2C-G, PIT-induced myocardial ischemia resulted in myocardial injury, as evidenced by increased LDH, CKand MPO activities, MDA and $\mathrm{Ca}^{2+}$ contents. However, the median dose of the drug combination (G: $12 \mathrm{mg} / \mathrm{kg}$, R: $0.15 \mathrm{mg} / \mathrm{kg}, \mathrm{S}: 6 \mathrm{mg} / \mathrm{kg}$ ) could significantly reduce the $\mathrm{LDH}, \mathrm{CK}$ and MPO activities, meanwhile, decrease the MDA and $\mathrm{Ca}^{2+}$ contents. While the combination with high (G: $24 \mathrm{mg} / \mathrm{kg}, \mathrm{R}: 0.3 \mathrm{mg} / \mathrm{kg}, \mathrm{S}: 12 \mathrm{mg} / \mathrm{kg}$ ) dosage showed evident effects on CK activity and MDA content, and the combination with low (G: 8 $\mathrm{mg} / \mathrm{kg}, \mathrm{R}: 0.1 \mathrm{mg} / \mathrm{kg}, \mathrm{S}: 4 \mathrm{mg} / \mathrm{kg}$ ) dosage only exhibited prominent function on CKactivity, with no significant difference on other detection indexes. Based on the comprehensive analysis of the above indicators, after administration of different doses of the combination, the median

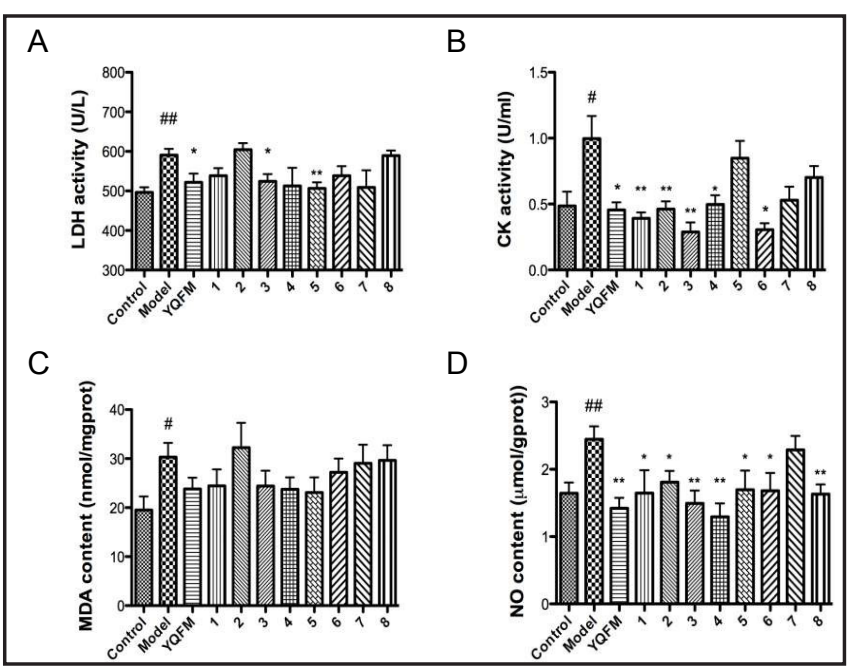

Fig. 3. Effect of different combinations based on uniform design in isoproterenol-induced myocardial ischemia mice. On the third day, mice were administered with isoproterenol (sc). After $1 \mathrm{~h}$, blood and tissue samples were collected for detection. (A) content. (D) Myocardial NO content. Arrangement of uniform experiment (group 1-8) was shown in Table 3. Results were presented as mean $\pm \mathrm{SEM}$. ${ }^{\#} \mathrm{P}<0.05$, ${ }^{\# \#} \mathrm{P}<0.01$ vs. Control group without myocardial ischemia injury, ${ }^{*} \mathrm{P}<0.05$, ${ }^{* *} \mathrm{P}<0.01$ vs. group treated with myocardial ischemia injury alone. $n=10$. Serum LDH activity. (B) Serum CK activity. (C) Myocardial MDA 
dosage exerted observably cardioprotective effect compared with the efficacy of high-dose and low-dose (Table 13). Therefore, the proportion and dosage of optimum combination (G: R: S, 12: $0.15: 6,18.15 \mathrm{mg} / \mathrm{kg}$ ) was obtained through the orthogonal experiment. In addition, it's worth noting that different proportion of combinations were got in two acute myocardial ischemia models, thus, we couldn't get the accurate results only by single index. Further investigations through the uniform design combining multiple indexes analysis should conducted and validated, finally obtained the optimal combination with the best comprehensive effect.

The optimization on the proper proportion of the multicomponent drug GRS by uniform design

Uniform design experimental screening results of the combination GRS on isoproterenol and pituitrin induced myocardial ischemia models. As shown in Fig. 3, serum LDH and CK activities, myocardium MDA and NO content increased significantly in ISO-induced myocardial ischemia mice. While compared with the model group, positive drug YQFM and the combination group 3 and 5 could significantly reduce the LDH activity. Simultaneously, positive drug YQFM and the combination group 1, 2, 3,4 and 6 could markedly decrease the $\mathrm{CK}$ activity. After given with the positive drug YQFM and the different combination groups, we found that YQFM and combination group $1,3,4,5$ could reduce the MDA content in a certain degree with no statistical difference. Meanwhile, YQFM and combination group 1, 2, $3,4,5,6,8$ could notably reduce the NO content.

As illustrated in Fig. 4, in PIT-induced myocardial ischemia mice, T-wave AUC, CK activity, MDA and NO content increased obviously. However, YQFM and the combination group 1, 2, 3,5 , 8 could significantly reduce the T wave elevation. Meanwhile, combination group 1, 3, 6 , 7, 8 markedly decreased the serum CK activity compared with the model group. In addition, MDA content was declined in the combination group 3, 5, 6 with a remarkable difference, and NO content was obviously dropped in YQFM and the combination group 1, 3, 4 .

Normalization processing of the results optimized by uniform experiment. Serum CK and LDH activities, myocardium MDA and NO content detected in ISO-induced myocardial 


\section{Cellular Physiology Cell Physiol Biochem 2018;45:1455-1471

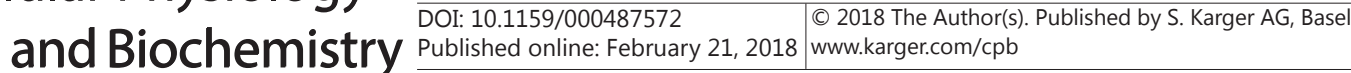 \\ Li et al.: A Strategy for Optimizing the Combination for Myocardial Ischemia}

ischemia model were all standardized (Table 14). After standardizing the data to "overall desirability" between 0 and 1 , we found that the factors were better when the value were smaller. The mathematical conversion method of Hassan was used to calculate the overall desirability $\left(\mathrm{d}_{\min }\right)$, and the formula is: $d_{\min }=\left(Y_{\max }-Y_{i}\right) /\left(Y_{\max }^{\min }-Y_{\min }\right)$. Finally, the geometric average was got based on the formula $O D=\left(d_{1} d_{2} d_{3} \ldots d_{k}\right)^{1 / k}$, and $k$ was the number of indexes. As exhibited in Table 15, the "overall desirability" was bigger, the efficacy of the combination was optimal. Therefore, the combination 3 (G: R: S, 6: 0.75: 6, $12.75 \mathrm{mg} / \mathrm{kg}$ ) was the most optimal group against the ISO-induced myocardial ischemia in mice.

In PIT-induced myocardial ischemia mice, electrocardiogram $\mathrm{T}$ wave AUC, serum CK activity, myocardium MDA and NO content were standardized (Table 16) the same as the above method. As shown in Table 17, the combination 3 (G: R: S, 6: 0.75: $6,12.75 \mathrm{mg} / \mathrm{kg}$ ) was also the most optimal group. And this results were also within the optimal proportion scope of the orthogonal experiment. Consequently, the best drug combination GRS (G: $6 \mathrm{mg} / \mathrm{kg}$; R: 0.75 $\mathrm{mg} / \mathrm{kg}$; S: $6 \mathrm{mg} / \mathrm{kg}$ ) was obtained through the orthogonal and uniform experiments screening.

Activity verification of the optimum combination on myocardial ischemia injury

In this section, three acute or chronic myocardial ischemia models were employed to validate the efficacy and function characteristics of the optimum combination 3 (G: $6 \mathrm{mg} /$ kg; R: $0.75 \mathrm{mg} / \mathrm{kg}$; S: $6 \mathrm{mg} / \mathrm{kg}$ ). Meanwhile, combination 1 (G: $12 \mathrm{mg} / \mathrm{kg}$; R: $0.15 \mathrm{mg} / \mathrm{kg}$; S: $6 \mathrm{mg} / \mathrm{kg}$ ) and combination 2 (G: $6 \mathrm{mg} / \mathrm{kg}$; R: $0.75 \mathrm{mg} / \mathrm{kg} ; \mathrm{S}: 12 \mathrm{mg} / \mathrm{kg}$ ) screened via orthogonal experiment, and the combination 4 (G Rg1: G Rb1: DT13: Sch A, 9:6:5:4, $18 \mathrm{mg} /$ $\mathrm{kg}$ ) authorized in our lab for the treatment of cardio-cerebral ischemic diseases before [23], were all used to compare their effects against myocardial ischemia injury.

Activity validation of the combinations against myocardial ischemia reperfusion injury. As noticed in Fig. 5, 30 min of ischemia and $24 \mathrm{~h}$ of reperfusion resulted in myocardial injury, as evidenced by increased LDH and MPO activities, $\mathrm{Ca}^{2+}$ and MDA content, and morphological alterations. Compared with the model group, combination 1 could only obviously reduce the LDH activity and $\mathrm{Ca}^{2+}$ content, combination 2 just significantly decreased the LDH activity, while combination 3 could extremely reduce the LDH and MPO activities, $\mathrm{Ca}^{2+}$ and MDA content. And combination 4 could markedly dropped the LDH and MPO activities, and the MDA content. In conclusion, combination 3 obtained through the above selection could significantly ameliorate the myocardial ischemia reperfusion injury, and exerted the equivalent myocardial protective effects compared to the positive drug YQFM.

In addition, the histopathological examination from MI/R mice' heart tissues exhibited widespread myocardial structural disarray, increased necrosis and fusion area, and a 
Fig. 5. Activity verification of the selected optimum combination GRS on C57 mice of myocardial ischemia and reperfusion injury. Mice were subjected to $0.5 \mathrm{~h}$ ischemia and $24 \mathrm{~h}$ reperfusion. Positive drug YQFM and combination 1-4 were administered after 20 min ischemia. After $24 \mathrm{~h}$ reperfusion, blood and tissue samples were collected for detection. (A) Serum LDH activity. (B) Myocardial $\mathrm{Ca}^{2+}$ content. (C) Myocardial MPO activity. (D) Myocardial MDA content. (E) Histopathological changes of representative myocardium sections were measured by HE staining (200×magnification). (F) Scores measurement of histopathological changes. Combination 1: G: $12 \mathrm{mg} / \mathrm{kg}$, R: $0.15 \mathrm{mg} / \mathrm{kg}$, S: 6 $\mathrm{mg} / \mathrm{kg}$; combination 2: G: $6 \mathrm{mg} / \mathrm{kg}$, R: $0.75 \mathrm{mg} /$ $\mathrm{kg}$, S: $12 \mathrm{mg} / \mathrm{kg}$; combination 3: G: $6 \mathrm{mg} / \mathrm{kg}$, R: $0.75 \mathrm{mg} / \mathrm{kg}$, S: $6 \mathrm{mg} / \mathrm{kg}$; combination 4: G Rg1: G Rb1: DT13: Sch A, 9:6:5:4, $18 \mathrm{mg} / \mathrm{kg}$. Results were presented as mean \pm SEM. ${ }^{~} \mathrm{P}<0.05$, ${ }^{\# \#} \mathrm{P}<0.01$ vs. Control group without myocardial ischemia reperfusion injury, ${ }^{*} \mathrm{P}<0.05,{ }^{* *} \mathrm{P}<0.01$ vs. group treated with myocardial ischemia reperfusion injury alone. $n=6$.

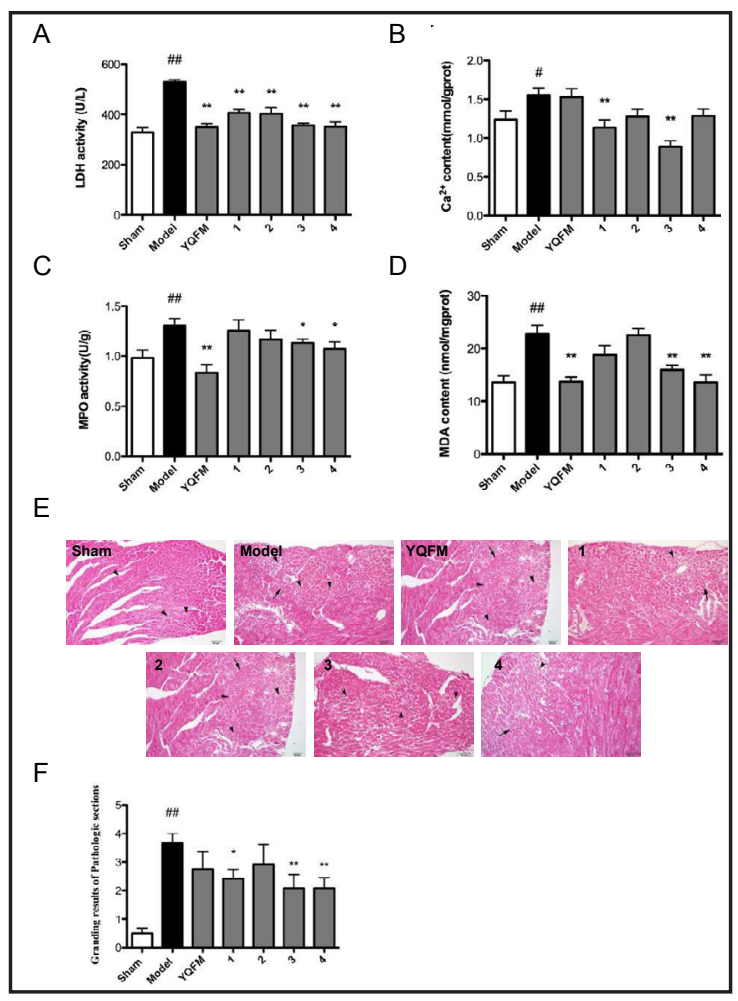

Fig. 6. Activity verification of the selected optimum combination GRS on ICR mice of chronic intermittent hypoxia injury. Mice were exposed to chronic intermittent hypoxia for 28 days in a chamber. After 28 days hypoxia, tissue samples were collected for detection. (A) Cardiac index. (B) Myocardial MDA content.

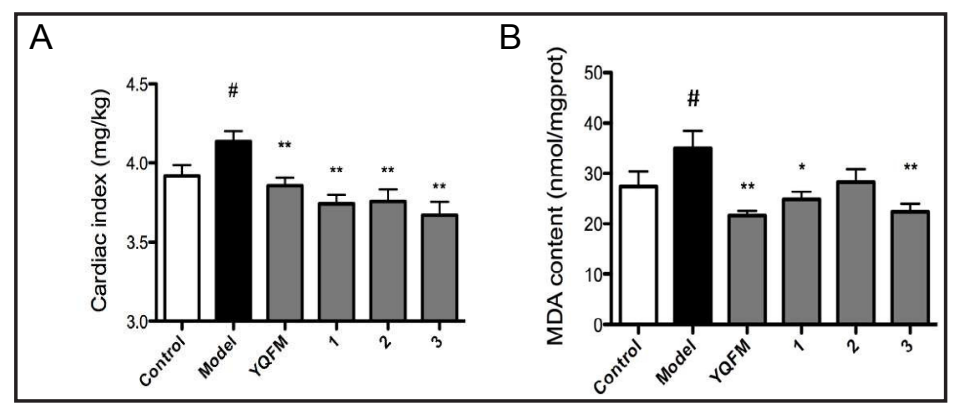
Combination 1: G: $12 \mathrm{mg} / \mathrm{kg}, \mathrm{R}$ :

$0.15 \mathrm{mg} / \mathrm{kg}$, S: $6 \mathrm{mg} / \mathrm{kg}$; combination 2: G: $6 \mathrm{mg} / \mathrm{kg}$, R: $0.75 \mathrm{mg} / \mathrm{kg}$, S: $12 \mathrm{mg} / \mathrm{kg}$; combination 3: G: $6 \mathrm{mg} /$ $\mathrm{kg}$, R: $0.75 \mathrm{mg} / \mathrm{kg}$, S: $6 \mathrm{mg} / \mathrm{kg}$. Results were presented as mean $\pm \mathrm{SEM}$. " $\mathrm{P}<0.05$ vs. Control group without chronic intermittent hypoxia injury, ${ }^{*} \mathrm{P}<0.05,{ }^{* *} \mathrm{P}<0.01$ vs. group treated with chronic intermittent hypoxia injury alone. $n=10$.

large number of inflammatory cells infiltrating the myocardial tissue. By contrast, the histological features became typical of normal cardiac structure or mild architectural damage with distinct amelioration after the combination 1,3 , 4 treatment with different efficacy. The effect of combination 3 and 4 was superior to the combination 1 and 2. Moreover, combination 3 , with removing an active compound and only two-thirds dosage compared with combination 4, exhibited
Table 18. The analysis of the components interaction relations in GRS. Formula is $\mathrm{y}=\mathrm{k}(\mathrm{a}+\mathrm{b}) /(1-(1-\mathrm{ka})(1-$ $\mathrm{kb})$ ), ka indicates the efficacy of using drug a alone, $\mathrm{kb}$ indicates the efficacy of using drug $\mathrm{b}$ alone, $\mathrm{k}(\mathrm{a}+\mathrm{b})$ indicates the efficacy of combined $a$ and $b ; y>1$ means synergistic effect, $y=1$ means additive effect, $\mathrm{y}<1$ means antagonistic effect

\begin{tabular}{lccc}
\hline & CK-MB & cTn-I & Infarct size \\
\hline y (G, R) & 1.2898 & 1.3019 & 0.6686 \\
y (G, S) & -0.2509 & 1.1601 & 0.6827 \\
y (R, S) & 0.7955 & 0.6930 & 0.5046 \\
y (G, R, S) & 1.2356 & 1.2871 & 0.7123 \\
\hline
\end{tabular}


Fig. 7. Activity verification of the optimum combination GRS and the relations of three components on C57 mice of acute myocardial infarction injury. Mice were subjected to $24 \mathrm{~h}$ ischemia. After $24 \mathrm{~h}$ ischemia, blood and tissue samples were collected for detection. Serum CK-MB concentration. (B) Serum cTn-I concentration. (C) Representative images of TTC stained myocardial infarct area. (D) Graphic representation of myocardial infarct size. Results were presented as mean \pm SEM. \#\# $\mathrm{P}<0.01$ vs. Control group without

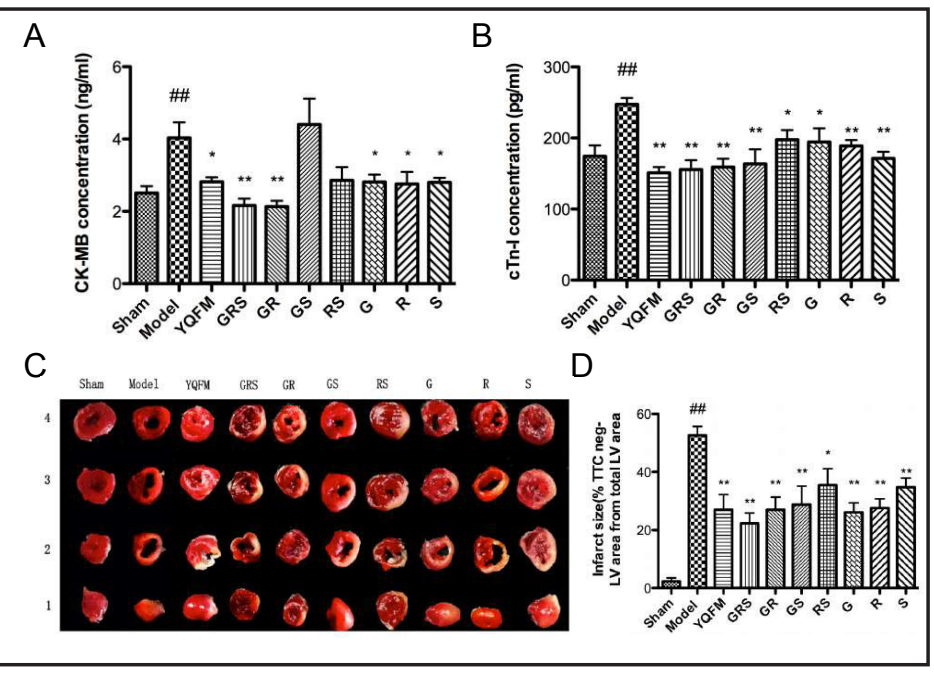
myocardial infarction injury, ${ }^{*} \mathrm{P}<0.05,{ }^{* *} \mathrm{P}<0.01$ vs. group treated with myocardial infarction injury alone. $\mathrm{n}=10$.

the similar function in improving myocardial ischemia reperfusion injury, which reflected the advantages of combination 3 to some extent.

Activity validation of the combinations against chronic intermittent hypoxia injury. As shown in Fig. 6, after continuous hypoxia for 28 days, the cardiac index of model mice showed a significant increase compared with the control group, meanwhile, the content of MDA in myocardial tissue also increased markedly. After administering different drug combinations, we found that both 3 combinations could markedly reduce the pathological changes of edema and congestion caused by hypoxia. Moreover, combination 3 could extremely remarkably decrease the oxidative damage with the similar efficacy to YQFM, which indicated that combination 3 had a certain improvement effect on chronic intermittent hypoxia injury.

Activity validation of the combination and the relations of three components against acute myocardial infarction injury. The above results showed that combination 3 could inhibit calcium overload, decrease oxidative damage, inflammation, and myocardial pathological changes with the exact curative effect. Furthermore, the relations of three components in combination 3 were further investigated, and the efficacy of combination 3 , the combination of two components or single component were compared in acute myocardial infarction model. As illustrated in Fig. 7, serum CK-MB and cTn-I concentrations significantly increased in model group, while the combination GRS and GR notably reduced the serum CK-MB and cTn-I concentrations. When compared with the G, R, S alone or its combinations, GRS and GR showed the optimum protective effect against the acute myocardial infarction. In addition, TTC staining results showed that GRS exhibited the best efficacy in suppressing the increase of infarct size, and the combined use of drugs was superior to single or combination of two compounds.

Furthermore, according to Webb fractional product method (Table 18), the compounds in GR and GRS had a synergistic effect on indicators CK-MB and cTn-I, and GS exerted a synergistic effect on cTn-I, while the RS had no synergistic effect. The characteristics of bioactive components in multicomponent drug GRS derived from Sheng-Mai-San for the treatment of myocardial ischemia, compared with the combination GR, needs our further investigation. 


\section{Cellular Physiology Cell Physiol Biochem 2018;45:1455-1471

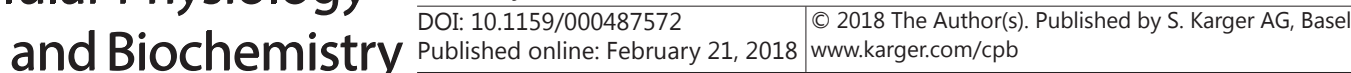 \\ Li et al.: A Strategy for Optimizing the Combination for Myocardial Ischemia}

\section{Discussion}

Optimization design of multicomponent drug on the basis of TCM effective ingredients is an effective way to inherit the advantages of TCM formula and develop modern TCM. And related technological research system of multicomponent drug design based on TCM effective ingredients is the key technical aspect to realize the modernization of TCM formula and should become the focus of research [24, 25]. Due to the complexity of components in TCM formula, the application of statistical experimental design methods and mathematical models may extremely contribute to the efficient searches for the potent drug combinations. Quantitative pharmacology is a branch of discipline that quantitatively study the rule of pharmacological actions using mathematical and statistical methods, which plays a more and more important role in the development of new drugs and the treatment of clinical drugs [26-29].

The mechanism of ISO-induced myocardial ischemia is due to the contracted coronary artery, strengthened cardiac contractility, increased myocardial oxygen consumption, and finally resulted in myocardial infarction in short time [30]. Mice injected with ISO led to acute myocardial ischemia which increased the demand of oxygen supply, and once the oxygen was in short supply, the body could not afford time to complete the compensatory response and eventually resulted in death of heart energy shortage. In addition, the PITinduced myocardial ischemia model is also widely used for the investigation of antimyocardial ischemia drugs. Pituitrin is extracted from the pituitary of animals, containing vasopressin and oxytocin. Vasopressin could directly make the blood vessels, especially the capillaries and small arteries including coronary artery contract, thus resulted the increased blood pressure and led to myocardial ischemia. Meanwhile, vasopressin could also shrink the small blood vessels of the whole body and cause increased cardiac workload, as well as to aggravate the symptoms of Qi deficiency in heart [31]. In present study, myocardial ischemia models were induced by ISO and PIT in mice, and data were obtained by orthogonal design. Then, the experimental results were secondarily processed through the application of variance analysis and multiple regression analysis. And finally, two optimal proportions range of the effective components combination were obtained.

Simultaneously, two combinations obtained via orthogonal experiment were further validated in PIT-induced myocardial ischemia mice. Through comparing the effects of different doses of drug combination on each index which contained the serum CK and LDH activities, the content of MDA and $\mathrm{Ca}^{2+}$ and MPO activity in myocardium, we found that the combination with the dosage of $18.15 \mathrm{mg} / \mathrm{kg}$ (G: R: S, 12: 0.15: 6) could significantly reduce the myocardial injury with the best efficacy. In summary, different multicomponent combinations were got through different animal models, which indicated that accurate results could not be obtained only relying on a single index. Uniform experiment design was further needed to screen out the optimum combination with comprehensive effects combined with multiple indexes analysis.

The method of uniform experimental design was put forward by two Chinese scholars Kaitai Fang and Yuan Wang [32]. Compared with the symmetrical comparability characteristic of the orthogonal design, the uniform design focused more on uniform distribution, which thereby led to the increased number of levels in experiment, but with little addition of test number of times [33]. Myocardial ischemia models induced by ISO and PIT were used in uniform design to explore the proper proportion of effective ingredients from Sheng-MaiSan through the optimization of multiple indicators using "overall desirability" [34]. The best results got via the uniform experiment showed little differences with the optimal results, and could represent the optimum screening combination.

In view of this, the concept of "overall desirability" was introduced in our present study. After the data were standard processed to "overall desirability" between 0 and 1 , we found that the factors were better when the value were smaller. The overall desirability $\left(\mathrm{d}_{\min }\right)$ was calculated using the mathematical conversion method of Hassan, and the formula is: $d_{\min }=\left(Y_{\max }-Y_{i}\right) /\left(Y_{\max }-Y_{\min }\right)$. Finally, the geometric average of overall desirability was 
obtained through the formula OD $=\left(\mathrm{d}_{1} \mathrm{~d}_{2} \mathrm{~d}_{3} \ldots \mathrm{d}_{\mathrm{k}}\right)^{1 / \mathrm{k}}$, and $\mathrm{k}$ is the number of indicators. After the conversion, the greater of the "overall desirability" showed the better protection on myocardial ischemia. In this study, myocardial ischemia models induced by ISO and PIT were prepared, and the indicators which reflected the different pathological injury mechanism in myocardial ischemia, including CK and LDH activity in serum, the content of MDA and NO in myocardium, electrocardiogram T wave area under the curve, were measured. Then, the effects of eight different active components combinations in the uniform design were compared. After the experimental data were normalized, the value of overall desirability is bigger, and the efficacy of the combination is better. Comprehensive analysis of the results in Table 15 and 17, it could conclude that the effectiveness of combination 3 (G: $6 \mathrm{mg} / \mathrm{kg}$, R: $0.75 \mathrm{mg} / \mathrm{kg}, \mathrm{S}: 6 \mathrm{mg} / \mathrm{kg}$ ) is optimal and this proportion is also in the range of screening results in orthogonal experiment. Therefore, the optimal combination was $\mathrm{G}$ with the dosage of $6 \mathrm{mg} / \mathrm{kg}$, R with the dosage of $0.75 \mathrm{mg} / \mathrm{kg}$ and S with the dosage of $6 \mathrm{mg} / \mathrm{kg}$ through the twice screening of orthogonal experiment and uniform design.

In addition, the protective effects of the screened combination were further validated in three myocardial ischemia models compared with the best combinations screened via orthogonal experiment and the former authorized combination in our lab [23]. Three mice models of myocardial ischemia were induced by myocardial ischemia/reperfusion, chronic intermittent hypoxia and acute myocardial infarction. Myocardial ischemia/reperfusion injury in mice was induced by ligation of the left descending coronary artery, involving calcium overload, oxygen free radical injury, inflammation and other damage, and simulated myocardial infarction induced by clinical coronary heart disease. After reperfusion, the oxygen in the blood could react with the dissolved substances of damaged myocardium cells to form the secondary injury in myocardium [35]. The model of chronic intermittent hypoxia in mice could simulate the heart palpitations and cardiac hypertrophy, eventually lead to the cardiac dysfunction and heart failure, meanwhile, could also simulate the apparent indications of deficiency of both Qi and Yin syndrome [22]. Moreover, the acute myocardial infarction was induced by ligation of the left anterior descending coronary artery, which caused serious and lasting regional myocardial ischemia due to a sharp reduction or interruption in the blood supply of the coronary artery [36]. Our study was consistent with the investigation mode of multi-model and multi-index screening method.

In present study, our results indicated that combination 3 could markedly ameliorate the myocardial injury caused by acute or chronic myocardial ischemia, and reduce the serum $\mathrm{LDH}$ activity, $\mathrm{Ca}^{2+}$, MDA and MPO content in myocardium, improve the cardiac pathological morphology. At the same time, this optimized combination 3 significantly reduced the serum CK-MB and CTn-I activities, which served as the first line of biological detection of acute myocardial infarction in the American Heart Association and the Heart Disease Foundation [37]. The combination 3 showed the comprehensive effects against myocardial ischemia, calcium overload, oxidative damage, inflammation and pathological changes, which reflected the characteristic of multi-pathways in exerting pharmacological effects with the equivalent myocardial protective efficacy compared to Sheng-Mai preparations. Meanwhile, this combination GRS exhibited the advantages of the quality control with specific components and reduced dosage, which provided some pharmacological evidences for further development of new modern Chinese drug for prevention and treatment of acute or chronic cardiovascular diseases basing on Chinese patent medicine with affirmative therapeutical effect.

Furthermore, the relations of three components in combination 3 were explored, and compared the efficacy of combination GRS, the combination of two components or single component in acute myocardial infarction model. Combination GRS, compared to G, R and S, could significantly reduce the concentration of serum CK-MB and CTn-I, and decrease myocardial infarct size, which demonstrated the advantages of combination GRS for myocardial ischemia. It was noteworthy that the combination GR exhibited the similar cardioprotective effect compared with GRS. Compound G was isolated from ginseng and recognized as prominent physiological bioactive ginsenosides. Various pharmacological

\section{KARGER}




\section{Cellular Physiology Cell Physiol Biochem 2018;45:1455-1471

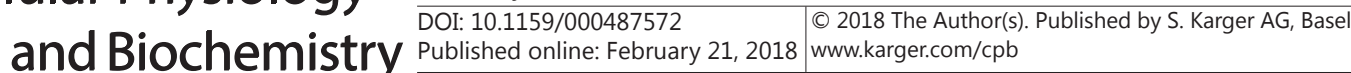 \\ Li et al.: A Strategy for Optimizing the Combination for Myocardial Ischemia}

studies showed that ginsenoside Rb1 could inhibit myocardial cell necrosis and apoptosis against myocardial ischemia injury via resistance of calcium overload and anti-apoptotic effect [38]. Compound $\mathrm{R}$ in combination is a major bioactive steroid sapogenin that is found in the roots of Ophiopogon japonicus and has been reported to exert cardiovascular protection through anti-inflammatory and anti-thrombotic activities [39]. Compound S from the lignans exhibited anti-oxidative effect and inhibited the lipid peroxidation damage in myocardial ischemia injury [40]. Whereas, the researches on effective drug combinations in multicomponent drug designs based on clinical effective TCM prescriptions are rare. One of the representative investigation is that applying formula ShenMai as an example, the combination (Panaxadiol: Panaxatriol: Ophioponins $=1: 2: 2$ ) produced by the proposed QCAR-based method showed the better effect on the reduction of acute myocardial infarct area and serum enzyme activities [41], which was similar to the combination GR in our present study. Formula ShenMai is also widely used for clinical myocardial ischemia diseases, which suggests that ginseng and Radix Ophiopogonis or the combination of its effective components are supposed to represent the part efficacy of the whole formula. Therefore, the function characteristics and the molecular mechanisms of anti myocardial ischemia injury in combination GRS and its individual component derived from the formula Sheng-Mai-San, compared to GR, deserves further investigation.

\section{Conclusion}

Our findings demonstrated that the optimized multicomponent drug GRS, based on orthogonal and uniform design, could exert significant cardioprotection against myocardial ischemia injury with similar effect compared to Sheng Mai preparations, which might provide some pharmacological evidences for further development of new modern Chinese drug for cardiovascular diseases basing on traditional Chinese formula with affirmative therapeutic effect.

\section{Acknowledgements}

This research work was supported by the National Natural Science Foundation of China (No. 81603328, No. 81573719, No. 81774150), Natural Science Foundation of Jiangsu Province (BK20160761), Project funded by China Postdoctoral Science Foundation (2016M600456, 2017T100425) and Graduate Innovation Fund of Huahai Pharmaceutical (CX16S-006HH).

\section{Disclosure Statement}

There is no conflict of interest.

\section{References}

$>1$ Bi Y, Jiang Y, He J, Xu Y, Wang L, Xu M, Zhang M, Li YC, Wang TG, Dai M, Lu JL, Li M, Chen CS, Lai SH, Wang WQ Wang LH, Ning G: Status of Cardiovascular Health in Chinese Adults. J Am Coll Cardiol 2015;65:10131025.

- Yellon DM, Hausenloy DJ: Myocardial Reperfusion Injury. N Engl J Med 2009;357:1121-1135.

3 Turer AT, Hill JA: Pathogenesis of Myocardial Ischemia-Reperfusion Injury and Rationale for Therapy. Am J Cardiol 2010;106:360-368.

4 Corson TW, Crews CM: Molecular Understanding and Modern Application of Traditional Medicines: Triumphs and Trials. Cell 2007;130:769-774. 


\section{Cellular Physiology Cell Physiol Biochem 2018;45:1455-1471 and Biochemistry \begin{tabular}{l|l} 
DOI: 10.1159/000487572 2018 The Author(s). Published by S. Karger AG, Basel & (c)
\end{tabular}

5 Lu J, Pan W, Hu Y, Wang Y: Multi-target drugs: the trend of drug research and development. Plos One 2012;7:e40262.

6 Zhang Z, Wang Z, Li P, Zhang W, Li X, Huang Q, Wang Y: The pharmacodynamic evaluation of QKL combination herbs on focal cerebral ischemia-reperfusion injury. Chinese Pharmacol Bull 2006;22:964967.

7 Wang L, Zhou G, Liu P, Song J, Liang Y, Yan X, Xu F, Wang B, Mao J, Shen Z, Chen S, Chen Z: Dissection of mechanisms of Chinese medicinal formula Realgar-Indigo naturalis as an effective treatment for promyelocytic leukemia. P Natl Acad Sci USA 2008;105:4826-4831.

-8 Edginton A, Theil F, Schmitt W, Willmann S: Whole body physiologically-based pharmacokinetic models: their use in clinical drug development. Expert Opin Drug Met 2008;4:1143-1152.

-9 Lalonde R, Kowalski K, Hutmacher M, Ewy W, Nichols D, Milligan P, Corrigan B, Lockwood P, Marshall S, Benincosa L, Tensfeldt T, Parivar K, Amantea M, Glue P, Koide H, Miller R: Model-based drug development. Clin Pharmacol Ther 2007;82:21-32.

10 Zheng QS, He YC, Yang J, Xu L, Lu Y, Liu H, Chen J, Sun R: An approach for the analysis of pharmacodynamic interactions and the simulation of combined response. Chinese Pharmacol Bull 2007;23:1106-1112.

11 Liu Q, Li JQ Wang J, Li JP, Janicki JS, Fan DP: Effects and Mechanisms of Chinese Herbal Medicine in Ameliorating Myocardial Ischemia-Reperfusion Injury. Evid-Based Compl Alt 2013;2013:925625.

12 Wang NL, Chang CK, Liu YL, Lin C, Lin M: Shengmai San, a Chinese herbal medicine protects against rat heat stroke by reducing inflammatory cytokines and nitric oxide formation. J Pharmacol Sci 2005;98:1-7.

13 Zheng H, Chen Y, Chen J, Kwong JSW, Xiong W: Shengmai (a traditional Chinese herbal medicine) for heart failure. Cochrane Database Syst Rev. 2011;16:CD005052.

14 Zhan SY, Fan XH, Zhang F, Wang Y, Kang LY, Li Z: A proteomic study of Shengmai injection's mechanism on preventing cardiac ischemia-reperfusion injury via energy metabolism modulation. Mol Biosyst 2014;12:674-677.

$15 \mathrm{Xu}$ LH: Therapeutic effect of YiQiFuMai in patients with chronic congestive heart failure. Med Inform 2009;22:2418-2419.

16 Wang YQ Liu CH, Zhang JQ, Zhu DN, Yu BY: Protective effects and active ingredients of Yi-Qi-Fu-Mai sterile powder against myocardial oxidative damage in mice. J Pharmaco Sci 2013;122:17-27.

17 Wang YQ Zhang JQ, Liu CH, Zhu DN, Yu BY: Screening and identifying the effective protective effect ingrediernts on myocardial injury from Sheng-Mai-San. Pharm Biol 2013;51:1219-1227.

18 Kim JH: Cardiovascular diseases and Panax ginseng: a review on molecular mechanisms and medical applications. J Ginseng Res 2012;36:16-26.

19 Cheng HY, Hsieh MT, Wu CR, Tsai FH, Lu TC, Hsieh CC, Li W, Lin Y, Peng W: Schizandrin protects primary cultures of rat cortical cells from glutamate-induced excitotoxicity. J Pharmacol Sci 2008;107:21-31.

-20 Kou JP, Tian Y, Yan J, Yu BY: Antithrombotic activities of Aqueous Extract from Radix Ophiopogon japonicus and Its Two Constituents. Biol Pharm Bull 2006;29:1267-1270.

21 Gao HE, Lei YH, Shang XY, Huang ZM, Zuo L, Boucher M, Fan QA, Chuprun JK, Ma XL, Koch WJ: A novel and efficient model of coronary artery ligation and myocardial infarction in the mouse. Circ Res 2010;107:1445-53.

-22 Chai CZ, Kou JP, Zhu DN, Yan YQ Yu BY: Mice exposed to chronic Intermittent hypoxia simulate clinical features of deficiency of both Qi and Yin Syndrome in traditional Chinese medicine. Evid Based Complement Alternat Med 2010;1-7.

23 Yu BY, Kou JP, Zhang J, Zhu DN, Qi J, Yan YQ: China Patent 2007;ZL200710132029 (5).

24 Guo L, Wang J: Effects of ingredient study in traditional Chinese medicine research. China J Chin Mater Med 2009;34(5):503-505.

25 Huang X, Xie H, Shi J, Song J, Zheng Q: Advances in quantitative pharmacology. Chin J Clin Pharmacol Ther 2009;14:601-612.

26 Dimasi J, Feldman L, Seckler A, Wilson A: Trends in risks associated with new drug development: success rates for investigational drugs. Clin Pharmacol Ther 2010;87:272.

27 Trott 0, Olson A: AutoDock Vian: Improving the speed and accuracy of docking with a new scoring function, efficient optimization, and mutithreading. J Comput Chem 2010;31:455-461.

28 Zheng QS, He YC, Yang J, Xu L, Lu YH, Liu HX, Chen JC, Sun RY: An approach for the analysis of pharmacodynamic interactions and the simulation of combined response. Chinese Pharmacol Bull 2007;23:1106-1112. 


\section{Cellular Physiology Cell Physiol Biochem 2018;45:1455-1471

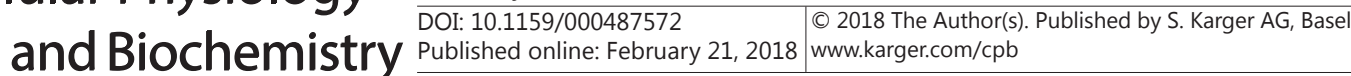

Li et al.: A Strategy for Optimizing the Combination for Myocardial Ischemia

29 Chen JC, Pan YJ, Li XS, Sun J, Liu HX, Sun RY, Zheng QS: Quantitative approach for calculation of pharmacodynamic interactions and simulation of combined response. China J Chin materia medica 2008;33:2029-2033.

-30 Guo JH, Yong YH, Aa JY, Cao B, Sun RB, Yu XY, Huang JQ Yang N, Yan LL, Li XX, Cao J, Aa N, Yang ZJ, Kong XQ, Wang LS, Zhu XX, Ma XH, Guo ZX, Zhou SP, Sun H, Wang GJ: Compound danshen dripping pills modulate the perturbed energy metabolism in a rat model of acute myocardial ischemia. Sci Rep 2016;6:37919.

-31 Pagliaro P, Moro F, Tullio F, Perrelli M, Penna C: Cardioprotective pathways during reperfusion: focus on redox signaling and other modalities of cell signaling. Antioxid Redox Signal 2011;14:833.

32 Fang KT, Shiu WC, Pan JX: Uniform Design Based on Latin Squares. Statistica Sinica 1999;9:905-912.

-33 Liang HQ Yang JE, Tang JM, Wu CC, Li HS, Chen SD: Optimization of dosage ratio of chlorogenic acid and gardenia glycosides in the treatment of rats with fatty liver disease induced by high-fat feed. J Tradit Chin Med 2016;36(5):683-688.

34 Wang YZ, Fang XL, Li YJ, Zhang ZW, Han LM, Sha XY: Preparation, characterization of paclitaxel-loaded pluronic P105 polymeric micelles and in vitro reversal of multidrug resistant tumor. Acta Pharm Sin B 2008;43:640-646.

35 Bernink F, Timmers L, Beek A, Diamant M, Roos S, Rossum A: Progression in attenuating myocardial reperfusion injury: an overview. Int J Cardiol 2014;170:261-269.

36 Gao L, Liu Y, Guo S, Yao R, Wu LM, Xiao LL, Wang Z, Liu YZ, Zhang YZ: Circulating long noncoding RNA HOTAIR is an essential mediator of acute myocardial infarction. Cell Physiol Biochem 2017;44:1497-1508.

37 Anand I, Florea V, Fisher L: Surrogate end points in hearts failure. J Am Coll Cardiol 2002;39:1414-1421.

-38 Lee CH, Kim JH: A review on the medicinal potentials of ginseng and ginsenosides on cardiovascular diseases. J Ginseng Res 2014;38:161-166.

39 Huang YL, Kou JP, Ma L, Song JX, Yu BY: Possible mechanism of the anti-inflammatory activity of ruscogenin: role of Intercellular adhesion molecule-1 and nuclear factor-kappaB. J Pharmacol Sci 2008;108:198-205.

40 Li F, Tan YS, Chen HL, Yan Y, Zhai KF, Li DP, Kou JP, Yu BY: Identification of schisandrin as a vascular endothelium protective component in YiQiFuMai Powder Injection using HUVECs binding and HPLC-DADQ-TOF-MS/MS analysis. J Pharmacol Sci 2015;129:1-8.

41 Wang Y, Yu LY, Zhang L, Qu HB, Cheng YY: A Novel Methodology for Multicomponent Drug Design and Its Application in Optimizing the Combination of Active Components from Chinese Medicinal Formula Shenmai. Chem Biol Drug Des 2010;75:318-324. 